\title{
1 Introducción
}

Aunque la caracterización del queísmo es, como veremos, una cuestión que está lejos de haber quedado resuelta, partimos inicialmente de una interpretación amplia del fenómeno según la cual este tiene lugar en aquellos entornos sintácticos en los que se supone ausente una preposición requerida por determinadas clases de palabras (verbos, sustantivos, adjetivos, etc.) y cuya presencia es manifiesta en otros contextos (Arjona 1978; Gómez Torrego 1999; Rabanales 2005; San Martín 2016). Estas variantes elididas llevan compitiendo siglos con las correspondientes alternativas preposicionales, como revelan los ejemplos (1) al (12) en muestras de habla separadas por varios siglos, y a propósito de idénticas construcciones. Al mismo tiempo, obsérvese cómo en muchos de estos casos el responsable de la variación es un mismo hablante:

(1) Jueves a .5. Haviendo enterado que después de haver resuelto un negocio en el Consejo se havía dado horden a uno de los secretarios que añidiese o quitase algo de lo que havia quedado acordado en el Consejo (Diario de Cristóbal de Crespí, 1654).

(2) ... e tenido propósito de no suplicar para mí cosa alguna al Arçobispo, mi señor, ni en esta ocasión suplico otra, sino que continúe la merced que con tan larga mano a comentado a hazerme; estoi mui enterado de que lo cuida esto más que io (Un epistolario de Bernardo José Aldrete, 1613).

(3) Papá Noel me ha traído unos pendientes, que me ha dicho mi madre que le han costao... y encima, me he enterao yo también que valen doscientos o trescientos euros (Macrocorpus sociolingüístico de Castellón y su área metropolitana ${ }^{1} 25,2000$ ).

(4) ¿Te has enterado de que hay una cena en Villar Palasí, en el colegio donde estuvimos en la EGB? (MCSCS 25, 2000).

(5) ... pues recibe Vm. las cartas del correo antes que se repartan a las demás, se sirva mandar que un alguacil se ponga en el lugar conveniente (Carta de Mayans a Blas Jover, 1733).

(6) ... la comuniqué a Luis Antonio Muratori, bibliotecario del duque de Módena, que citó i publicó las instrucciones de las Antigüedades Bracarenses antes de que su autor las divulgase (Carta de Mayans a Blas Jover, 1746).

(7) [Tenía] quince o dieciséis. Y llegué al instituto antes que se acabaran las clases (MCSCS 125, 2004).

(8) Yo no quería hacer daño, lo que pasa... los niños eran tan malos a veces que antes de que se metieran contigo te metías tú con ellos (MCSCS 125, 2004).

(9) En el dia 20, que aun continuaba la lluvia embió el Comandante Portugués un Cabo, y siete indios avisando lo mismo á su comisario, á quien pedia mas viveres (Diario de la frontera hispano-lusa, 1755).

(10) ... sobrevinieron algunas lluvias, que les impidieron salir hasta el dia 20, en que lo executaron con quatro Canoas medianas (Diario de la frontera hispano-lusa, 1755).

1 A partir de aquí, este corpus se identificará con las siglas MCSCS (para más detalles sobre este, véase §8.1).

Ә Open Access. (C 2022 José Luis Blas Arroyo and Mónica Velando Casanova, published by De Gruyter. (cc) BY-NC-ND This work is licensed under the Creative Commons Attribution-NonCommercial-NoDerivatives 4.0 International License.

https://doi.org/10.1515/9783110766851-001 
(11) ay sí! tengo un trauma, el día que me dijeron que los Reyes Magos eran los papás (MCSCS 202, 2006).

(12) yo que sé y: el aprecio y el amor por ciertas personas, eso, eso te llena mucho en: esta vida, yo creo que sí, hasta el día en que te mueras lo mejor es tener a alguien que: que piense en ti (MCSCS 202, 2006).

Los fragmentos (1) a (4) ilustran la variable lingüística en completivas dependientes de verbos y adjetivos relacionados aquí formal y semánticamente, como ocurre con el par enterar(se)/enterado. De estos, los números impares revelan las soluciones queístas, mientras que los pares dan cuenta de las variantes preposicionales. La consideración como queístas obedece al hecho de que la preposición aparece sin excepción en otros contextos sintácticos, como los ejemplificados a continuación en los mismos textos expuestos arriba:

(13) ... pues, estando S. E. enterado de la raçón que vería notoria en los papeles, no se podía dudar de su amparo en la justicia del Consejo (Diario de Cristóbal de Crespí, 1653).

(14) ... se lo dije a mi marido: ves, si: no te hubiera hecho caso y hubiera llamado y hubiera insistido, me hubiera enterado de lo que ocurría (MCSC 25, 2000).

El mismo criterio vale para otros casos de queísmo conjuntivo, como los ejemplificados en (5) a (8), y que esta vez tienen como protagonista a subordinadas circunstanciales introducidas por una locución adverbial, antes (de) que. En la historia del español, la pugna entre las formas con-(6) y (8)-y sin preposición(5) y (7) - ha sido una constante, con independencia de que el adverbio antes requiera también obligatoriamente del auxilio de una preposición en otras ocasiones, como revelan estos otros ejemplos:

(15) Señor. Yo me hallaba mui bien en Oliva antes de ver a V. Ex. i al Sr. Conde de Harrach, i ahora suspiro por no saber cómo he de pasar los días i las noches (Carta de Mayans al conde de Cervelló, 1752).

(16) Pues este verano practica, te levantas y te haces un enjuague de esos bucal, y: y te pones a cantar un ratillo por la mañana, y por la noche antes de acostarte (MCSCS 125, 2004).

Distinto es, sin embargo, el caso de variación exhibido en los fragmentos (9) a (12), para el que se reserva el concepto de queísmo pronominal (Gómez Torrego 1999; Amorós 2009), ya que en él la presencia/ausencia de la preposición afecta a subordinadas en las que el nexo no es una conjunción, sino un pronombre relativo homófono (que). Además, en esta alternancia sintáctica, que ha sido objeto de mucha menor atención en la bibliografía, ${ }^{2}$ la preposición más afectada no

2 De hecho, algunas obras de referencia recientes, como el diccionario de Alcaraz Varó/Martínez Linares (1997, 477) o el Diccionario panhispánico de dudas (2005), no abordan ningún caso de este tipo, por lo que parecen limitar el alcance del queísmo al conjuntivo. 
es de, como ocurre en los ejemplos anteriores, sino en. Y también a diferencia de los ejemplos de queísmo conjuntivo reseñados, en esta ocasión el sustantivo que actúa como antecedente de la construcción no subcategoriza obligatoriamente un sintagma preposicional en otros contextos sintácticos.

En suma, lo que revelan estos fragmentos es que el queísmo es un caso de variación pancrónico, que afecta a diferentes tipos de construcciones, y no solo a las completivas dependientes de ciertos verbos, como sucede con el que algunos autores consideran el reverso de un mismo fenómeno, el dequeísmo (García 1986; Schwenter 1999; Rabanales 2005; Guirado 2009). Los enunciados (17) a (20) ejemplifican esta otra variación en varios momentos de la historia:

(17) Sólo me admira que hayas llegado á quererme (Carta de Marcelino Menéndez Pelayo a Conchita Pintado, 1878).

(18) ... y no deja de admirarnos de que los facultativos de Paris no hallen un remedio para las almorranas (Carta de José Madrazo a su hijo Federico, 1838).

(19) ... si te has cargao enseguida el fin de semana, y eso no son ni vacaciones ni nada, entonces quiero decir que con un poco más de tiempo los fines de semana... (MCSCS 175, 2005).

(20) Hace poco en el periódico decían de que había una casa que los los dueños hablaban con: con las paredes porque hacían ruido (MCSCS 175, 2005).

Obsérvese cómo en estos fragmentos, la variante cero compite también con la alternativa preposicional, pero a diferencia de los ejemplos (1) a (4), la preposición no es exigida por los verbos $a_{d m i r a r}^{3}$ y decir en otras circunstancias. De ahí que el dequeísmo se interprete esta vez como la forma vernácula de la variable sintáctica, esto es, como aquella que carece de prestigio sociolingüístico. De hecho, en la comparación entre estos dos fenómenos que afectan al régimen verbal, las instituciones académicas indican que el queísmo «se percibe [en la actualidad] como una anomalía menor que el dequeísmo» (RAE/ASALE 2009, 3252). Por su parte, Gómez Torrego (1999, 2133-2134) señala otros motivos estructurales que los separan y por los que-a nuestro juicio, también-conviene considerarlos aparte. Además de la ya apuntada asociación del queísmo con entornos sintácticos más diversos que el dequeísmo, hay que recordar también que este último concierne exclusivamente a la preposición de, lo que no sucede con el queísmo, cuya nómina de partículas es bastante más amplia (de, $a$, por, en, con...), con independencia de que, en algunos tipos particulares, predominen más unas que otras. A ello hay que sumar que el queísmo es mucho más frecuente que el dequeísmo (McLauchlan 1982; Gómez Molina/Gómez Devís 1995; Almeida 2009a), tanto en el español americano como en el europeo. De hecho, mientras que la datación de este último no está del todo clara en la historia del español (DeMello 1995,

3 No así el pronominal admirarse. 
141; Gómez Molina/Gómez Devis 1995, 196; Bentivoglio/Sedano 2011, 178), existe un relativo consenso acerca de la antigüedad de las construcciones queístas, de las que encontramos numerosos testimonios ya desde el periodo medieval (Kany 1969, 408-411; Company Company 1992, 105-119; Del Moral 2004, 121-169; Herrero Ruiz de Loizaga 2005, 87-92).

Sobre las causas del queísmo se han esgrimido diversas razones, que van desde la fonética sintáctica-la elisión, por ejemplo, de la preposición de en contextos intervocálicos del tipo estoy seguro de-a la ultracorrección, especialmente entre los hablantes más conscientes de la estigmatización del dequeísmo, lo que arrastraría a la elisión de la partícula incluso en aquellos casos en los que esta es correcta (García Yebra 1990). Asimismo, se ha acudido al universal de la economía lingüística, un principio que iría en contra de la redundancia nexual, en la práctica presente en pocas lenguas, como el español y el portugués, pero no en otras muchas, incluidas las del mismo tronco romance (francés, italiano, catalán, etc.). Otro factor relevante es la analogía con estructuras parecidas, pero cuyos regímenes sintácticos difieren (Seco 1989, 199; Rabanales 2005, 415). Así, Gómez Torrego $(1999,2140)$ recuerda que construcciones como Concluyeron que presentarían un proyecto podrían explicar la difusión del queísmo en otras equivalentes del tipo Llegaron a la conclusión que... Y lo mismo sucedería con verbos como el pronominal acordarse, cuyos elevados índices de queísmo podrían explicarse por el cruce con recordar (Recuerdo que...); estructuras atributivas como está seguro (de) que, a partir de lo que sucede con el mismo adjetivo y el verbo ser (Es seguro que...); o, incluso, en locuciones conjuntivas del tipo en vista (de) que, por contagio con otras similares como una vez que o a no ser que.

Desde el punto de vista extralingüístico, hemos visto ya cómo la Nueva gramática académica (RAE/ASALE 2009) considera el queísmo como una «anomalía» menor que el dequeísmo, y añade que incluso «... se atestigua con frecuencia en los registros formales, y algunas de sus variantes están considerablemente extendidas» (2009, 3252). De hecho, en un cuestionario sobre actitudes hacia los fenómenos del dequeísmo y el queísmo en la ciudad de Valencia, Gómez Devis (1996, 315) obtuvo apenas un 15\% de estigmatizaciones del segundo, frente a índices mucho mayores del primero (70\%). Aun así, las instituciones académicas siguen considerando hoy como más recomendables y correctas las construcciones con preposición en colocaciones con verbos de apoyo (darse cuenta (de) que, dar la casualidad (de) que), locuciones conjuntivas (en caso (de) que), verbos pronominales (olvidarse (de) que) y no pronominales (insistir (en) que), y estructuras atributivas, como estar seguro (de) que, si bien reconocen que en muchos casos se está imponiendo la variante queísta, que en algunos es ya casi categórica (el caso de acordarse, por ejemplo). Por otro lado, la variación geográfica es también notable, especialmente entre uno y otro lado del Atlántico, de manera que el régimen de 
algunas construcciones puede diferir considerablemente entre unas variedades y otras. A este respecto, se ha destacado, por ejemplo, que las variantes queístas son en la actualidad más frecuentes en el español de América que en el europeo; o incluso que, en este último, la extensión del fenómeno se ve alentada en las comunidades del ámbito lingüístico catalán por convergencia con esta lengua, en la que el régimen sintáctico no contempla la duplicación nexual (Seco 1989; Gómez Torrego 1999).

Estas y otras conclusiones similares se han derivado de diversos estudios dialectológicos y, en menor medida, sociolingüísticos, acerca del queísmo contemporáneo en diferentes comunidades de habla del mundo hispánico (Arjona 1978; García 1986; Boretti de Macchia 1989; Carbonero 1991; Gómez Molina/Gómez Devís 1995; Gómez Devís 1996; Del Valle 1996-1997; Bentivoglio/Galué 1998-1999; Schwenter 1999; Del Moral 2004; Rabanales 2005; Guirado 2009; Almeida 2009a; 2009b; Gómez Molina 2013, entre otros). Sin embargo, es muy poco lo que sabemos acerca de la difusión de este fenómeno en la historia, y mucho menos sobre los factores lingüísticos y extralingüísticos que lo han condicionado en diferentes momentos. El propósito de esta investigación es, justamente, llenar esta laguna en el conocimiento sobre uno de los fenómenos sintácticos más singulares y persistentes en la diacronía del español. En particular, nuestros objetivos se centran en dar respuesta a las siguientes preguntas de investigación:

- ¿Cuál ha sido la extensión del queísmo en diferentes construcciones sintácticas a lo largo de la historia?

- ¿Ha habido cambios significativos en esa evolución?

- ¿Ha sido el queísmo un fenómeno unitario, condicionado por similares factores, con independencia de las construcciones en que aparece?

- ¿Cuál ha sido la profundidad histórica de los condicionantes lingüísticos y extralingüísticos en este fenómeno de variación?

- ¿De qué manera han afectado las tendencias centrales al comportamiento de algunas construcciones sintácticas e idiolectos particulares?

Para dar respuesta a estos interrogantes, y en el marco de la sociolingüística variacionista, llevamos a cabo un estudio pancrónico del fenómeno en cuatro momentos diferentes de la historia del español: 1) Siglos de Oro; 2) Periodo moderno (1700-1835); 3) Periodo contemporáneo (1875-1960); 4) Periodo actual (siglo XXI). Para ello nos servimos de un par de corpus que, aunque de naturaleza diferente, coinciden en una misma posición cercana al polo de la inmediatez comunicativa (Oesterreicher 2004) y, por tanto, a la concepción oralizante del habla. Dada la imposibilidad de contar con testimonios orales de los dos primeros periodos mencionados, y de buena parte del tercero, para su estudio nos servimos de un corpus histórico compuesto por textos escritos vinculados a esa inmediatez, en 
especial miles de cartas privadas redactadas por españoles de diversa condición social y dialectal (Blas Arroyo/Porcar/Velando y Vellón 2019). Por su parte, la fase actual se nutre de los materiales compilados en tres corpus orales representativos de otras tantas comunidades de habla peninsulares contemporáneas (Castellón, Madrid y Alcalá de Henares).

A diferencia de otras aproximaciones al análisis de la diacronía, en el presente estudio partimos del principio de 'responsabilidad ante los datos' (accountability) (Labov 1972), de tal manera que nuestra atención no se fija exclusivamente en la variante objeto de interés (en este caso, las construcciones queístas), sino también en aquellas que podrían ocupar su lugar, como sucede aquí con las alternativas preposicionales. Actuar de otra manera sería poner en peligro los objetivos de la investigación, ya que nada garantizaría que las conclusiones acerca del condicionamiento variable de las variantes queístas no pudieran servir también para explicar el de sus competidoras.

Al mismo tiempo, este principio del análisis está estrechamente vinculado con una aproximación cuantitativa al estudio de la variación y el cambio lingüístico. En particular, esta se basa en la consideración de diversas magnitudes y direcciones explicativas que se derivan de un análisis estadístico multivariante, en el que todos los predictores se consideran conjuntamente. El carácter predictivo de este análisis permite detectar qué factor o factores explican de una manera significativa la variación a la luz de las muestras disponibles, así como eventuales desenlaces de interacción o colinealidad entre estos, lo que permite salvar las limitaciones de una mera estadística bivariante, tradicional en el estudio diacrónico de la lengua. En concreto, en esta investigación nos servimos de un análisis de regresión logística de efectos mixtos, en el que se toman en consideración no solo predictores categóricos (como la polaridad o el sexo), sino también otros de naturaleza continua (el tiempo) y aleatoria (cada uno de los informantes o las estructuras sintácticas implicadas). La participación de estos últimos entraña casi siempre resultados más conservadores, pero, como contrapartida, mucho más fiables acerca de la verdadera incidencia de los condicionantes a partir de los datos disponibles. Por otro lado, dada la naturaleza pancrónica de nuestros objetivos, en el estudio aplicamos una metodología comparatista, de tal manera que las magnitudes cuantitativas se comparan entre los diferentes periodos reseñados. Ello nos permitirá obtener una imagen más ajustada acerca de cuáles han sido los derroteros por los que ha circulado la variable lingüística a través de la historia.

El libro se estructura de la siguiente manera. En el siguiente apartado (§2), resumimos algunos datos acerca del origen, la caracterización y la distribución actual de la variable lingüística. A este le sucederá, en §3, la codificación lingüística de la variable, capítulo en el que pasamos revista a las diferentes construcciones sintácticas analizadas, así como a los condicionantes lingüísticos y extralingüísticos que 
sometemos a examen. La descripción de las principales cuestiones metodológicas de la investigación será el objeto de interés de §4, en especial el corpus que sirve como base empírica para el estudio y el modelo de análisis variacionista utilizado. El apartado §5 representa el núcleo de la obra, ya que en él damos cuenta de los principales resultados en cada periodo, tanto globalmente como en cada una de las construcciones tomadas en consideración. Asimismo, en estos apartados dedicamos una atención específica a diversos desenlaces de la variación intradialectal, como la que tiene lugar en el seno de las distintas estructuras lingüísticas implicadas, o entre los individuos responsables de la variación, en especial de aquellos que están mejor representados en el estudio y cuyas preferencias podemos valorar con mayor detalle. Este análisis no solo de los factores que afectan al conjunto de la comunidad lingüística, sino también del modo en que esta variación se resuelve en el habla de determinados individuos o en construcciones lingüísticas particulares en cada periodo representa también una novedad hermenéutica en el estudio de la variación diacrónica.

El análisis del corpus histórico se cierra con los apartados $\S 6$ y $\S 7$, en los que analizamos la profundidad pancrónica de los condicionantes en la variación y los principales perfiles idiolectales observados en cada etapa, respectivamente. Ambos darán paso al estudio del español peninsular actual a partir de las muestras de español oral mencionadas más arriba. En este capítulo (§8), pondremos a prueba la incidencia de los factores ya analizados en el corpus histórico con el fin de comprobar qué líneas de continuidad o de ruptura se aprecian con respecto al pasado. Finalmente, en $§ 9$, sintetizaremos los principales resultados y las implicaciones teóricas y metodológicas más relevantes que se desprenden de la investigación. 
